\title{
Editorial
}

Journal of

Molecular Microbiology

\section{Science, Innovation and the Future of Humanity}

\author{
Milton H. Saier Jr. ${ }^{a} \quad$ J.T. Trevors ${ }^{b}$ \\ a Division of Biological Sciences, University of California at San Diego, La Jolla, CA, USA;

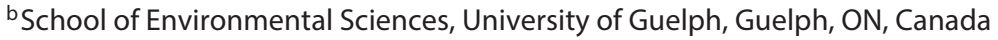

Local, national and international security are all promoted through the application of reliable scientific knowledge. This information can be used to establish and maintain personal and public health, and critical to this last goal, a detailed knowledge of microbiology (e.g., vaccines, proper storage and consumption of food, plant pathology, agricultural production, sewage and water treatment) is essential [Ales and Katial, 2004; Forrest et al., 2014]. While this conclusion is generally accepted worldwide, it may not be recognized that the evolution of a stable and equitable modern democracy also depends on factual information obtainable through science. This editorial deals with these issues.

Science is the only systematic method available to us for testing a hypothesis using observation, statistics and experimentation [Stolar, 1980]. Where religion ends, science begins. Oscar Wild said: "Science is the record of dead religions." What did he mean by this provocative statement? Religious myth represents a proposal, a hypothesis, as to how things are, or were or will be, and science uses the empirical method to test the accuracy of such proposals. Regardless of whether the religious postulate proves to be true or false, that postulate subsequently enters the realm of science; it is no longer a part of the unknown. It is no longer necessary to dogmatically claim truth for an idea that is unsubstantiated [De Cruz, 2017].

When used with a plausible, testable hypothesis and the independent replication of experiments observed by

\section{KARGER}

(C) 2017 S. Karger AG, Basel

E-Mail karger@karger.com

www.karger.com $/ \mathrm{mmb}$ different individuals, science is the most powerful tool we have for innovation and discovery, although luck is always helpful [Trevors et al., 2012]! Science tries to remove biases and subjectivity, minimizing the chance of incorrect conclusions. The scientific method starts with an observation or idea, progresses to a question that leads to a hypothesis and predictions, and these are then tested by experimentation and further observation [Silva, 2007]. This may involve using independent researchers and independently replicated experiments to arrive at robust conclusions. Rejection of a hypothesis through experimental investigation often leads to a new or improved postulate, closer to the truth, allowing the investigators to conduct new experiments. Data gaps can be filled, and fragmented knowledge can be better connected and often applied.

From the earliest use of the scientific method to the present, this method works with remarkable success if applied correctly. Science, when conducted at the highest level by credible researchers, makes every attempt to get it right, and incorrect conclusions are likely to be examined by numerous other independent investigators, providing incentive for anyone in the scientific community to publish correct data and conclusions the first time around, or suffer the consequences. The data, if correctly obtained and interpreted, leads to reliable conclusions. There will always be data gaps and fragmented knowledge, but the scientific method can be used to fill the gaps,

Milton H. Saier Jr.

Division of Biological Sciences

University of California at San Diego

La Jolla, CA 92093-0116 (USA)

E-Mail msaier@ucsd.edu 
dot the "I"s and cross the "T"s, while obtaining even more accurate details. The scientific process never ends, and for some, this is frustrating. But for others it provides a wonderful, lifelong challenge and a way to contribute to humanity. That's because some scientists are enthralled with the known, while others are excited about the unknown. The knowledge gained provides satisfaction to the scientists who participated in the generation of that knowledge, but the latter challenges the imagination, allowing scientists to conceptualize novel processes and then plan experimentation to test the possibilities.

Microbiology provides many examples where immense progress has been made in both basic and applied fields, primarily over the past 2 centuries, and basic discoveries are often responsible for applied advances. $\mathrm{Mi}$ crobiological research, which encompasses the disciplines of physiology, ecology, genetics, biochemistry and molecular biology now depends heavily on genome sequencing and bioinformatics [Sadiq et al., 2014]. The combined use of these last mentioned approaches, the first to generate data, and the second to try to understand and make sense out of the newly obtained results, has led to profound, transformative discoveries in individual and public health [Blount, 2015]. These include vaccine development and large-scale vaccine production [Titball, 2008], antibiotic and antiviral agent discoveries applied to the treatment of infectious diseases [Punina et al., 2015], and the development of increasingly accurate and rapid medical diagnostics [Perez and Villegas, 2015]. However, we have also come to appreciate the need for sanitation; humans require an ample supply of safe drinking water as well as essential products including food and medicines [Begley and Hill, 2010]. Further, we need to dispose off sewage effectively to maintain a healthy environment. However, it must also be recalled that exposure to microorganisms is largely responsible for the development of the immune system, and insufficient exposure can lead to a variety of health-threatening conditions such as asthma and certain types of allergies [Lynch and Boushey, 2016]. We now know that all of us depend on our bodily microbiome for both physical and mental health [Dinan and Cryan, 2017; Reddy and Saier, 2015; Rieder et al., 2017; Tang et al., 2014]. Thus, we need to rely on scientific discoveries as they unfold to determine our best courses of action.

We can now control many plant diseases, preventing former "natural disasters," leading to the potential for food security worldwide. We can also use molecular genetics to improve nutrition, taste and food production, and to overcome pesticide resistance [Schornack et al.,

Science, Innovation and the Future of Humanity
2013]. However, the full achievement of these prospects will require more than technical advances. We know that the human population is not living sustainably; we are using resources more rapidly than they can possible be regenerated. Food production, especially when confronted with extreme weather, droughts and wild fires, is no longer keeping up with our burgeoning population. We are on a collision course with dire consequences that will result in tremendous suffering, warfare and deaths throughout the world. Our population cannot continue to expand as it has since the beginning of the industrial revolution if we are ever able to achieve the desired goal of sustainability [Speidel et al., 2009].

Knowledge is at hand to implement the requisite changes, but the desire is not always there. This is because of ignorance, superstition in the form of mythological beliefs and a lack of global humanistic sympathies. We need to correct these conditions, beliefs and feelings to have a lasting civilization. How sad it would be if Bach, Beethoven and Brahms were to be lost forever. What a shame if the works of our great artists and writers were to be lost as well. We live in the transition zone, and may actually be accelerating our demise [Speidel et al., 2009; Tagle, 1993].

As some societies attempt to evolve modern democracies, they recognize that humanities, when integrated with the sciences, provide a more complete understanding of the desired goals; they allow us to recognize what we have in common with each other and with other living beings. Science and humanities thus support each other as we face global climate change and an increasing human population with finite resources [Parkes and Horwitz, 2009]. The world is, however, increasingly dominated by science, even if many world citizens do not understand the scientific method and its value. These individuals must somehow gain a basic appreciation of science so that they can benefit maximally and avoid irreversible mistakes.

World citizens must come to recognize the value of humanities. They need to respect humanity as a whole, and not just consider themselves, their families and their communities [Erratt, 2011]. Unfortunately, this type of appreciation is sometimes not fostered by what we currently see presented in the media. Yet, the media may provide the best sources for instilling these values. Just imagine the consequences if they were included in program messages through the media on a daily basis. In short, we need to think globally and long term, and then implement our newly found knowledge into practical solutions. We know what is required; now we must insure that the right decisions are made.

J Mol Microbiol Biotechnol 2017;27:128-132 DOI: $10.1159 / 000467401$ 
We now have a basic understanding of the organismal evolutionary process by which simple prokaryotic cells formed symbioses and cooperative communities to eventually generate increasingly complex organisms such as plants and animals [Thompson et al., 2012]. We also have an understanding of the oldest life forms on Earth for which we have fossil records - dating back about 3.5 billion years, and possibly as long as 3.8 billion years ago [Knoll, 2015]. This knowledge reminds us that it was not just "survival of the fittest" that drove our evolution, but also, and perhaps more importantly, cellular and organismal cooperation [Cohen, 2016]. We are not just competitive organisms; we are also symbiotic beings; we are altruistic; we cooperate with our microbiome to create a whole organismal consortium. And throughout the billions of years wherein life on Earth evolved, increasing the organization of organisms and communities, it has always been so.

As humans, we have a sense of community; we have humanitarian instincts, feelings and concern for others, and therefore, we act to alleviate human suffering [Gatchell et al., 2006]. We also have feelings for other living organisms and want to leave this planet, ensuring continued life for them. We see beautiful and unusual plants and animals, and hope our children and grandchildren will similarly be able to enjoy their qualities. We know that we could not survive without the essential products of photosynthesis. The continuance of all this requires that we implement programs of sustainability.

Our modern evolving democracies are increasingly dependent on science. Try to imagine a world without the use of science! For example, we need computing and methods of communications to record, analyze and report accurately on elections. Democracy depends on fair systems of representation, and gerrymandering, voter suppression and election practices that are designed to give certain groups more power and influence than others need to be counteracted. We need to take the money out of politics so the richest are not favored over those of lesser means. Above all, we need a populace that is educated so they know what political parties and candidates have their better interests in mind, and therefore elect candidates who do not seek office only to extract personal benefits [Trevors and Saier, 2010].

Education is both expensive and time consuming. In a democracy, everyone needs to be informed and vote in accordance with their understanding of the issues. They need to understand the fundamentals of matter and energy conservation (thermodynamics) to recognize how limited our resources on Earth are. We need to develop infrastructure to facilitate communication, both nationally and internationally. Education seems to be our primary long-term solution so everyone recognizes the need for international security and environmental protection of our shared, singular biosphere [Trevors and Saier, 2010]. Everyone must come to recognize the need for sustainable birth control. Only if we can bring our population into reign will we be able to create a sustainable society. Once again, we have the knowledge; now we need to implement that knowledge into proper actions.

Science and its practitioners have shaped our concepts of the modern world everywhere, at every level of organization, from the individual to all of humanity, and from the subatomic level to the unimaginable scope of the expanding universe [Chaisson, 2014]. We need to reflect at a profound level why misinformation, outright lies, undocumented beliefs and destructive policies are given even the slightest amount of consideration when not accompanied by independently obtained data that support them. Since many members of our species will believe anything without supporting evidence, educators have an immense worldwide challenge, one that is probably far more difficult than the usual scientific problems that we normally try to solve [Trevors and Saier, 2010]. If some humans want to believe, or for selfish reasons, claim, that we have infinite resources in the face of hard data that prove otherwise, they are not to be trusted or put in positions of authority. They are profoundly ignorant in both informational quality and quantity. Unfortunately, ignorance and selfish deeds do not contribute constructively either to modern science or to the evolution of modern democracies with humanistic values.

Why do some humans prefer to ignore facts and knowledge based on rigorous research? Why would they choose to accept beliefs and opinions without documentation? Did the educational systems fail them? Did they fail themselves by not seeking accurate answers? Do they not know how to examine problems of importance for their own survival? Is the infrastructure not present for them to seek a reliable education? Is the correct knowledge suppressed and propagated due to selfish motives? Do many people simply not care, or are they too lazy to make the effort required to understand? The answers are multifaceted, but unfortunately, these are the most difficult to obtain.

A sustainable future depends on science, critical thinking, innovation and its applications as well as on correct legislation [Chow and Labov, 2008]. We are challenged by global change and an increasing human population, but we also face the issues of corruption and failed
130

J Mol Microbiol Biotechnol 2017;27:128-132 DOI: $10.1159 / 000467401$
Saier Jr./Trevors 
representation in government. We suggest that more countries need to evolve into stable, representative, modern democracies [Hardy et al., 1986]. If scientists, who have given humanity the knowledge required to influence our modern world for better, we must insure correct information transfer to the constituencies of all democracies. We must be more than scientists; we must be public servants who bring established principles and concepts to our communities and the world [Dudo and Besley, 2016; Fischhoff, 2013; Lupia, 2013; Scheufele, 2014]. The worldwide distribution of peer reviewed scientific knowledge via computing and the internet is well established in many countries. Artificial intelligence and robotics that will soon replace numerous human jobs are also progressing. Others in our societies must come to appreciate the need for rigorous standards of accuracy and humanistic thought. They must recognize the value of their own freewill, and never choose to ignore the knowledge obtained through the world of science upon which we all depend.

What are the answers? We must consider all aspects; certainly acquisition of accurate knowledge and humanistic values will provide a good start. But can we achieve this goal in time? Or ever? These are the questions that plague us daily.

Scientists are held to a high intellectual standard and bear the burden of evidence [111th Annual Meeting of the American Association of Colleges of Pharmacy, 2010]. Replicated experiments and observations must be available before formulating conclusions that lead to suggestions for future hypothesis testing. Is it too much to ask non-scientifically trained people to apply logic and critical thinking to their personal and professional lives? We must all recognize that obtaining the best available answers, as our knowledge advances, potentially contributes positively to humanity.
Use of the scientific method is a welcome approach as opposed to claiming accuracy for the first things that come to mind. The latter approach, which led to thousands of mythological treatises, has propagated misinformation and inappropriate action, which is of little value to humanity. The world does not need to hear the views of uninformed people trying to communicate their beliefs on, for example, vaccines or public health, when they lack scholarly knowledge of the relevant fields of study [Leitner, 2003]. Thus, we do not turn to a plumber for legal advice or a carpenter for health-related diagnoses. Researchers have the potential to favorably shape the future if they are not hindered by poorly informed members of society [Trevors and Saier, 2010].

Our species faces numerous threats, many of which result from our own actions. These threats include drugresistant microbes, emerging infectious diseases, and water, food and energy shortages [Speidel et al., 2009]. Climate change will lead to increasingly detrimental disasters, but the application of science can help us ameliorate the consequences [Gutierrez and LePrevost, 2016; Semenza et al., 2012; Speidel et al., 2009; Sutherst, 2004]. This will require that societies recognize the desirability of supporting the sciences, both basic and applied.

In summary, science is the search for factual truth. It is rooted in established, systematic, unbiased, theoretical and empirical approaches involving the scientific method. It requires the participation of many societies, and all elements within these societies, without discrimination, in a global attempt to understand nature and our universe. We cannot afford to suppress scientifically tested information, but we must recognize and dismiss undocumented and untestable beliefs based on mythology and inaccurate thoughts. Scientifically sound facts and principles can then be our guide for constructive future development.

\section{References}

111th Annual Meeting of the American Association of Colleges of Pharmacy, Seattle, Washington, July 10-14, 2010. Am J Pharm Educ 2010;74:96

Ales NC, Katial RK: Vaccines against biologic agents: uses and developments. Respir Care Clin N Am 2004;10:123-146.

Begley M, Hill C: Food safety: what can we learn from genomics? Annu Rev Food Sci Technol 2010;1:341-361.

Blount ZD: The unexhausted potential of E. coli. Elife 2015;4.

Science, Innovation and the Future of Humanity
Chaisson EJ: The natural science underlying big history. ScientificWorldJournal 2014;2014: 384912.

Chow I, Labov JB: Working together to address challenges to the teaching of evolution. CBE Life Sci Educ 2008; 7:279-283.

Cohen IR: Updating Darwin: information and entropy drive the evolution of life. F1000Res 2016;5:2808

De Cruz H: Religion and science; in Zalta N (ed): Stanford Encyclopedia of Philosophy. Stanford, The Metaphysics Research Lab, 2017.
Dinan TG, Cryan JF: The microbiome-gut-brain axis in health and disease. Gastroenterol Clin North Am 2017;46:77-89.

Dudo A, Besley JC: Scientists' prioritization of communication objectives for public engagement. PLoS One 2016;11:e0148867.

Erratt TD: Ethics education in undergraduate pre-health programs. The contribution of undergraduate colleges and universities to the ethical and moral development of future doctors in the medical and dental professions. Tex Dent J 2011;128:698-706. 
Fischhoff B: The sciences of science communication. Proc Natl Acad Sci USA 2013;110(suppl 3):14033-14039.

Forrest GN, Van Schooneveld TC, Kullar R, Schulz LT, Duong P, Postelnick M: Use of electronic health records and clinical decision support systems for antimicrobial stewardship. Clin Infect Dis 2014;59(suppl 3):S122S133.

Gatchell V, Forsythe V, Thomas PR: The sustainability of community-based therapeutic care (CTC) in nonemergency contexts. Food Nutr Bull 2006;27:S90-S98.

Gutierrez KS, LePrevost CE: Climate justice in rural southeastern united states: a review of climate change impacts and effects on human health. Int J Environ Res Public Health 2016; 13:189.

Hardy JJ, Thomas CL, Utiger RD: Characteristics of thyroxine $5^{\prime}$-deiodinase activity in human liver. Am J Med Sci 1986;292:193-197.

Knoll AH: Paleobiological perspectives on early microbial evolution. Cold Spring Harb Perspect Biol 2015;7:a018093.

Leitner WW: Myth, menace or medical blessing? The clinical potential and problems of genetic vaccines. Expert Opin Biol Ther 2003;3:1-4.

Lupia A: Communicating science in politicized environments. Proc Natl Acad Sci USA 2013; 110(suppl 3):14048-14054.

Lynch SV, Boushey HA: The microbiome and development of allergic disease. Curr Opin Allergy Clin Immunol 2016;16:165-171.

Parkes MW, Horwitz P: Water, ecology and health: ecosystems as settings for promoting health and sustainability. Health Promot Int 2009;24:94-102.
Perez F, Villegas MV: The role of surveillance systems in confronting the global crisis of antibiotic-resistant bacteria. Curr Opin Infect Dis 2015;28:375-383.

Punina NV, Makridakis NM, Remnev MA, Topunov AF: Whole-genome sequencing targets drug-resistant bacterial infections. Hum Genomics 2015;9:19.

Reddy BL, Saier MH: Autism and our intestinal microbiota. J Mol Microbiol Biotechnol 2015; 25:51-55.

Rieder R, Wisniewski PJ, Alderman BL, Campbell SC: Microbes and mental health: a review. Brain Behav Immun 2017;pii:S0889-1591(17) 30016-8.

Sadiq SM, Hazen TH, Rasko DA, Eppinger M: Ehec genomics: past, present, and future. Microbiol Spectr 2014;2:EHEC-0020-2013.

Scheufele DA: Science communication as political communication. Proc Natl Acad Sci USA 2014;111(suppl 4):13585-13592.

Schornack S, Moscou MJ, Ward ER, Horvath DM: Engineering plant disease resistance based on TAL effectors. Annu Rev Phytopathol 2013;51:383-406.

Semenza JC, Houser C, Herbst S, Rechenburg A, Suk JE, Frechen T, Kistemann T: Knowledge mapping for climate change and food- and waterborne diseases. Crit Rev Environ Sci Technol 2012;42:378-411.
Silva AJ: The science of research: the principles underlying the discovery of cognitive and other biological mechanisms. J Physiol Paris 2007;101:203-213.

Speidel JJ, Weiss DC, Ethelston SA, Gilbert SM: Population policies, programmes and the environment. Philos Trans R Soc Lond B Biol Sci 2009;364:3049-3065.

Stolar MH: Interpretation of research data: hypothesis testing. Am J Hosp Pharm 1980;37: 1539-1545.

Sutherst RW: Global change and human vulnerability to vector-borne diseases. Clin Microbiol Rev 2004;17:136-173.

Tagle Ra Jr: No choice. Human beings must continue to be fertile and to increase, but they must do so responsibly. Integration 1993;36: 26-27.

Tang F, Reddy BL, Saier MH Jr: Psychobiotics and their involvement in mental health. J Mol Microbiol Biotechnol 2014;24:211-214.

Thompson AW, Foster RA, Krupke A, Carter BJ, Musat N, Vaulot D, Kuypers MM, Zehr JP: Unicellular cyanobacterium symbiotic with a single-celled eukaryotic alga. Science 2012; 337:1546-1550.

Titball RW: Vaccines against intracellular bacterial pathogens. Drug Discov Today 2008; 13 : 596-600.

Trevors JT, Pollack GH, Saier MH Jr, Masson L: Transformative research: definitions, approaches and consequences. Theory Biosci 2012;131:117-123.

Trevors JT, Saier MH: Education for humanity. Water Air Soil Pollut 2010;206:1-2. 